\title{
Uma abordagem schutziana do problema da igualdade-desigualdade ${ }^{1}$
}

\author{
A schutzian approach to the problem \\ of equality-inequality
}

Hisashi Nasu*

\begin{abstract}
Resumo: "Igualdade" é um dos valores predominantes na sociedade moderna. É praticamente assumido como dado que igualdade tem que ser garantida, aprofundada e alcançada em qualquer esfera. Enquanto tal, a ideia de igualdade continua a ser um dos princípios básicos da teoria social moderna desde que J.J. Rousseau discutiu o tema. Contudo, igualdade não é um conceito definitivo, mas "sensitivo" (H. Blumer) e "vazio", ou seja, deve assumir várias conotações. Muitos pesquisadores interessados no problema de igualdade-desigualdade como um fenômeno social envidaram esforços para preenchê-lo com alguns conteúdos. Suas discussões tendem a ajustar seus focos sobre "Igualdade de quê?" (A. Sen), examinar vários tipos de igualdade e desenhar uma conclusão sobre qual tipo de igualdade deve ser dado maior prioridade sobre outros, fundada sobre alguns pressupostos básicos assumidos como dados. Um atribui maior prioridade, por exemplo, à "igualdade de recursos", outro à "igualdade de capacidade", um terceiro à "oportunidade igual ao bem-estar", e um quarto ao "acesso igual aos benefícios" e assim não há maneira de reconciliar um com o outro.

Pesquisas empíricas conduzidas por tais discussões podem acumular muitos dados e resultados em quantidade, mas não podem desenvolver uma teoria adequada de igualdade-desigualdade e não podem aprofundar a compreensão do fenômeno social de igualdade-desigualdade. Neste sentido, seria melhor, eu penso, consultar a contribuição de Schutz ao Fifteenth Symposium of the Conference on Science, Philosophy and Religion proferida na Columbia University em 1955.

Este artigo procura examinar o significado da discussão fenomenológica de Schutz sobre igualdade para o debate sobre o problema de igualdade-desigualdade em particular, e o significado da sua teoria social fenomenológica em geral.
\end{abstract}

* Professor no Departamento de Sociologia da Waseda University, Tóquio. E-mail: <hnasu@ waseda.jp>.

1 Publicado originalmente em Essays in celebration of the founding of the Organization of Phenomenological Organizations, Ed. CHEUNG, Chan-Fai; Chvatik, Ivan; Copoeru, Ion; Embree, Lester; Iribarne, Julia; Rainer Sepp, Hans. Publicado em www.o-p-o.net, 2003. Traduzido do original em inglês por Hermílio Santos.

\begin{tabular}{|c|c|c|c|c|c|}
\hline Civitas & Porto Alegre & v. 11 & n. 3 & p. 395-408 & set.-dez. 2011 \\
\hline
\end{tabular}




\begin{abstract}
Equality" is one of the most prevailing value in modern society. It is almost taken for granted that equality has to be guaranteed, advanced, and achieved in any sphere. As such, the idea of equality continues to be one of the basic principles of modern social theory since J. J. Rousseau discussed it.

Equality is, however, not a definitive but a "sensitizing" (H. Blumer) and "empty" concept, i.e., it might take on various connotations. Many scholars interested in the problem of equality-inequality as a social phenomenon therefore have made efforts to fulfill it with some contents. Their discussions tend to adjust their focuses on "Equality of What?" (A. Sen), examine various types of equality, and draw a conclusion on which type of equality has to be given higher priority over others, founded on some basic assumptions taken for granted. One assigns higher priority, for example, to "equality of resource," another to "equality of capability," a third to "equal opportunity to the welfare," and a forth to "equal access to the advantage," and then there is no way to reconcile to each other.

Empirical researches led by such discussions might accumulate many data and findings in quantity, but could not develop an adequate theory of equality-inequality, and could not also deepen understanding of the social phenomenon of equality-inequality. In this respect, we had better, I think, consult Schutz's contribution to the Fifteenth Symposium of the Conference on Science, Philosophy and Religion held at Columbia University in 1955.

This essay aims to examine the significance of Schutz's phenomenologically oriented discussion about equality to the inquiry into a problem of equality-inequality in particular, and the significance of his phenomenologically oriented social theory in general.
\end{abstract}

\title{
Introdução
}

O problema da igualdade é um dos mais antigos problemas, que tem sido discutido a partir de várias perspectivas e por várias disciplinas. Mas, recentemente, estão ocorrendo novos tipos de desigualdade, por exemplo, aqueles envolvendo a assim-chamada globalização e a comunicação na internet. Embora estejam tornando sem sentido as fronteiras nacionais artificiais e tornando possível para todas as pessoas compartilhar informações comuns, estão produzindo novas desigualdades, por exemplo, "minorias tecnológicas" por meio da alfabetização ou do analfabetismo em computador. O problema da igualdade está assumindo um maior significado. Este artigo é dedicado a procurar uma maneira adequada de abordar o problema da igualdade.

\section{Como o problema da igualdade-desigualdade foi abordado?}

1 "Igualdade significa tratar pessoas semelhantes de uma maneira semelhante". Esta famosa definição de igualdade de Aristóteles é absolutamente verdadeira. Ninguém pode refutar esta definição como tal. Esta definição, 
entretanto, nada afirma sobre igualdade em um sentido real e não pode ser aplicada em casos concretos e reais. Tanto a denotação quanto a conotação desta definição dependem das denotações e conotações dos termos "pessoas semelhantes" e "maneira semelhante", que constituem a definição, e o último deles pode ser estendido ou limitado ou modificado sem restrição. Dessa maneira, poderíamos interpretar quaisquer relações sociais tanto como relações iguais ou desiguais de acordo com esta definição pela simples razão de que cada um é único, em sentido estrito, e é diferente de qualquer outro. A definição aristotélica de igualdade, que depende da suposição de que "a natureza fez todos os homens iguais", é intrinsicamente vazia.

2 Depois de Aristóteles, muitas discussões filosóficas e éticas foram dedicadas a preencher esses termos vazios, como "pessoas semelhantes" e "maneira semelhante", com conteúdos mais substantivos e gerais. Essas discussões trazem as questões de quais tipos de pessoas diferentes devem ser tratadas justificadamente de quais maneiras diferentes. Parece-me, entretanto, que por ora não existe qualquer resposta acordada e compartilhada.

2.1 Mas uma opinião parece ser compartilhada em diversas literaturas sobre igualdade: de que há dois aspectos ou fases ao afirmar que pessoas são tratadas igualmente. Uma delas é igualdade em termos de oportunidade (igualdade de oportunidade) e a outra é igualdade em termos de renda (igualdade de renda). Igualdade de oportunidade está centrada em possibilidades iguais para "cada pessoa" realizar suas próprias capacidades ou de receber benefícios ou recompensas; e igualdade de renda está centrada na distribuição igual de "recursos valiosos" para "cada pessoa". Uma vez que o foco do primeiro é na possibilidade, pode ser chamada de igualdade formal. Em contraste, igualde de renda pode ser chamada de igualdade substantiva.

3 No estágio inicial da sociedade moderna, estas duas igualdades poderiam ser perseguidas ao mesmo tempo sem contradição. Na França no final do século XVIII, por exemplo, a burguesia, que surgiu contra a sociedade de status chamada Antigo Regime, encorajada pelo Iluminismo, especialmente pela concepção de direitos humanos, começou a demandar direitos iguais de participação na política (igualdade de oportunidade). Por outro lado, visto do ponto de vista da nação-estado, a distribuição igual de recursos era um dos objetivos imediatos e principais a serem perseguidos (igualdade de renda), porque o cidadão homogêneo era um requisito para a administração do estado burguês. Nesse período, essas duas demandas foram perseguidas uma ao lado da outra.

3.1 Entretanto, quando um sistema de distribuição de recursos foi estabelecido e instituído, suficiente para manter um padrão mínimo de vida "comum" no 
século XX, uma contradição surgiu entre estas duas igualdades. A garantia de igualdade de oportunidade conduziu à desigualdade de renda. Por exemplo, as condições de competição desregulamentada (igualdade de oportunidade) estão inclinadas para conduzir ao oligopólio, que resulta em desigualdade de renda. Assim, são necessárias discussões, por um lado, sobre como alcançar igualdade de oportunidade em reconciliação com igualdade de renda e, de outro lado, sobre "igualdade de quê" (Sen, 1992). Pode-se dizer que o objetivo dessas discussões é estabelecer os princípios normativos de acordo com os quais relações sociais concretas podem ser julgadas em termos de igualdadedesigualdade.

4 Quanto à sociologia, várias pesquisas empíricas foram conduzidas em várias áreas, por exemplo, estratificação, relações raciais, educação, casamento ou relações de gênero. A maior parte delas não se ocupa dos princípios normativos da igualdade em si. Ao contrário, presumindo explicitamente ou tacitamente alguns princípios normativos concebidos e elaborados por discussões filosóficas e éticas, ou em noções de senso comum secularizadas desses princípios filosóficos e éticos, elas questionam que métodos de pesquisa e quais indicadores quantitativos ou escalas são adequados para verificar se as relações sociais sob investigação são iguais ou desiguais. Os objetivos de suas pesquisas são identificar e verificar em que sentido as relações sociais são iguais ou desiguais e quais fatores estão "impondo barreiras" artificiais para alcançar igualdade (Harrison, 2000, pp.371-72).

4.1 Contudo, penso que pesquisas empíricas sobre igualdade conduzidas por indicadores objetivos e quantitativos possuem sérios limites.

4.1.1 Primeiro, uma vez que não há qualquer concepção consensual sobre igualdade em nenhum campo, não há igualmente qualquer indicador objetivo de igualdade e desigualdade.

4.1.2 Segundo, se alguns indicadores ou escalas são inventadas para mensurar igualdade ou desigualdade em um determinado campo, fica sempre um sério problema. É um problema sobre sua adaptação aos fenômenos sociais. Um indicador quantitativo ou escala pode ser adotado somente quando fenômenos sociais já foram articulados ou circunscritos antes da adaptação. Contudo, nem indicadores quantitativos nem escala mencionam como articular ou circunscrever fenômenos sociais. Na verdade, posso encontrar duas pesquisas empíricas, ambas utilizando o mesmo indicador de distribuição desigual de renda, chamado "coeficiente Gini". Elas coletaram seus dados quantitativos corretamente por meio de suas próprias pesquisas de acordo com um método científico, calcularam o coeficiente de Gini de tais dados e chegaram a conclusões sobre a sociedade japonesa. Uma afirmou que poderia 
ser encontrado no Japão uma tendência à desigualdade de renda desde fins dos anos 1980 (Tatsuki, 1998) e a outra afirmou que de 1979 a 1994 não poderia ser encontrada qualquer tendência à desigualdade de renda no Japão (Ohtake, 2000).

4.1.3 Terceiro, se os mesmos dados são utilizados para fazer um julgamento sobre desigualdade, ainda existe uma possibilidade para as diferentes conclusões obtidas. Tenho também dois trabalhos que usam os mesmos dados coletados do mesmo projeto de pesquisa, um enorme projeto chamado "Pesquisa sobre estratificação social e mobilidade no Japão", realizada em 1995. É uma pesquisa que utiliza métodos amostrais e questionários. Esses dois trabalhos dependem exclusivamente dos mesmos dados quantitativos e chegam a resultados opostos. Ou seja, um afirma que no Japão pode ser encontrado uma forte tendência em direção a uma reprodução da "elite intelectual" (Sato, 2000), ou seja, temos um sistema fechado de mobilidade social no Japão, e a outra afirma, ao contrário, que essa tal "reprodução" não tem fundamento (Seiyama, 2000).

4.2 Gostaria de acrescentar que todos esses pesquisadores são bastante sérios e honestos, e não cometem equívocos no uso de métodos "científicos" e na leitura dos dados. Minha opinião é que este é um resultado do limite inerente ao método quantitativo em geral, que ele conduza a resultados contraditórios. Alguns positivistas frequentemente insistem que os dados quantitativos devem falar por si mesmos. Entretanto, dados não podem fornecer qualquer discurso por conta própria. Deve-se perceber honestamente e modestamente que é a interpretação do pesquisador que permite que dados quantitativos digam algo sobre alguma coisa.

5 Como demonstrado acima, diferentes ideias e pesquisas resultam em vários resultados sobre igualdade, às vezes contraditórios. Assim, deve-se questionar radicalmente qual postura ou perspectiva é a melhor a ser adotada em tais circunstâncias? Minha opinião é que é importante levar completamente em consideração que o problema de igualdade ocorre não nas esferas religiosas e científicas, mas na esfera social. Igualdade-desigualdade é um fenômeno social que nós, atores da cena social, experienciamos no processo de interação social com outros no mundo da vida cotidiana. Dessa maneira, pesquisadores interessados em igualdade-desigualdade têm que perceber honestamente que seus próprios constructos são "constructos do segundo nível, ou seja, constructos dos constructos realizados pelos atores na cena social" (Schutz, 1953, p.6). Assim, a tarefa dos cientistas sociais é, antes de tudo, descrever a maneira em que atores experienciam igualdade-desigualdade na cena social em seus mundos da vida cotidianos. Procurarei fazer isso na próxima seção. 


\section{Como as pessoas experienciam igualdade-desigualdade no mundo da vida cotidiano?}

\section{A. Experiência cotidiana de diferenças entre o outro e eu mesmo}

1 Eu, o homem adulto alerta (Schutz, 1953, p. 7; Husserl, 1962, p. 145-146), sei na atitude natural que eu sou único em sentido estrito.

1.1 Isso significa que eu sei que eu sou diferente de todos os outros em muitos aspectos e todo mundo é também diferente de cada um em muitos aspectos. Por exemplo, sou de "meia idade" e ele é "jovem". O tamanho dos meus sapatos é $25 \mathrm{~cm}$ e o tamanho dos sapatos do meu amigo A é de $26 \mathrm{~cm}$. Posso correr 100 metros em apenas 11 segundos e meu amigo B corre em 14 segundos.

1.2 Além disso, eu sei que sou diferente de outros não apenas de maneira individual, mas também de maneira social. Por exemplo, eu sou um "japonês" e ele é um "cidadão norte-americano". Eu sou um "professor universitário" e ele é um "bancário". Eu sou "casado" e ele é "solteiro".

1.3 Ademais, eu sei como tipificar o outro e eu próprio em uma dada situação. Em outras palavras, eu sei qual tipo de tipificação deve ser adotada em cada caso. Por exemplo, sei o caso em que tenho que reconhecê-lo e tratálo como um "cidadão norte-americano", e em que caso como um "homem jovem". Assumo que isso também é válido para o outro. Isso significa que tipificação está relacionada à definição da situação.

1.4 Quando eu me reconheço como um "professor universitário", eu o reconheço não como um "cidadão norte-americano" ou "solteiro", mas como um "bancário". Entretanto, eu também posso reconhecê-lo como um "cidadão norte-americano". Ao mesmo tempo, eu me reconheço, consciente ou inconscientemente, como um "japonês". Isso significa que auto-tipificação corresponde à tipificação do outro por mim (Schutz, 1953, p. 19).

1.5 Contudo, mesmo quando eu me reconheço como um "professor" e o outro como um "bancário", o outro pode não necessariamente me reconhecer como um "professor". Ele pode me reconhecer como um "japonês" ou como um "homem de meia-idade". Isso significa que a tipificação do outro por mim pode corresponder ou não à tipificação minha feita pelo outro. Quando a correspondência entre elas de fato ocorre, há maior possibilidade na interação entre o outro e eu próprio de comportarmos fluentemente de uma maneira esperada. Isso não significa, contudo, que tal correspondência é uma condição necessária ou suficiente para a interação exitosa. Ao contrário, quando tal correspondência não ocorre, nossa interação terá maior possibilidade de se deparar com obstáculos para suavizar o processo. 
2 Sei também que alguns sistemas de tipificação possuem sua própria ordem hierárquica e outros sistemas não. Quanto ao anterior, conheço igualmente a ordem hierárquica. Um sistema de tipificação das ocupações pode ser assumido como um exemplo do anterior. Sei que, de maneira geral, "professor universitário" é considerado superior ao "bancário". Ao contrário, não há qualquer ordem hierárquica entre o "japonês" e o "cidadão norteamericano". Dizer que não há qualquer ordem hierárquica deve ser distinguido claramente de afirmar que o "japonês" e o "cidadão norte-americano" estão ordenados no mesmo nível hierárquico.

2.1 Sei que deve haver uma ordem hierárquica entre os sistemas de tipificação. Por exemplo, na sociedade moderna, os tipos considerados superiores no sistema de ocupação devem ser assumidos como mais elevados que os tipos superiores no sistema de habilidades físicas.

3 Sei que há a expectativa que eu, um "professor universitário", tenha de agir de uma maneira diferente dele, "bancário", e devo ser tratado de uma maneira distinta de como ele seria. Isso significa que cada tipo social comporta uma expectativa particular e uma maneira particular de ser tratado.

4 Eu sei ou presumo que a maneira de tipificar os outros e a mim mesmo, as ordens hierárquicas dentro e entre sistemas de tipificação, as diferentes expectativas de ação e as diferentes maneiras de ser tratado de acordo com as diferentes tipificações, todas elas não são unicamente minhas, mas compartilhadas por todos os membros da minha sociedade. De maneira mais precisa, aqueles que as compartilham são considerados tacitamente como sendo membros desta sociedade.

5 Caso a história mencionada acima seja verdadeira (dos itens 1 a 4 nesta sessão), não devo experienciar desigualdade. Ser tratado de uma maneira diferente nem sempre é incompatível com a ideia de "igualdade". Se eu reconheço que eu sou apreendido como de um certo tipo individual ou social e tratado de uma maneira diferente da maneira como meu amigo é tratado, eu não percebo que eu fui tratado desigualmente. Dessa maneira, tenho que questionar, em que momentos aparece a experiência de igualdade ou desigualdade?

\section{B. Experiência cotidiana de igualdade-desigualdade}

$1 \mathrm{O}$ que eu gostaria de assinalar antes de qualquer coisa é que somente através da interação com outros, ou, mais precisamente, através da atitude de outros em relação a mim e/ou a reação de outros à minha ação que eu experiencio igualdade ou desigualdade. Sem interação não surge nem igualdade nem desigualdade. Isso é válido para mim, que experiencio igualdade ou desigualdade, não enquanto a pessoa em questão, mas enquanto um terceiro. 
2 Não deve ser necessário afirmar que todas as interações não são necessariamente momentos em que igualdade ou desigualdade aparecem. Dado que eu sou tratado por outros de uma certa maneira e eu reconheço isso como diferente da maneira como alguém é tratado, alguém que eu penso que deva ser tratado da mesma maneira como eu sou, possivelmente devo experienciar "desigualdade".

3 Tal experiência de "desigualdade" não é, entretanto, suficiente para emergir o problema de igualdade-desigualdade. Mesmo que eu experiencie tal possível "desigualdade", não identifico isso como uma desigualdade real a ser removida, quando eu percebo e me convenço de que um tal tratamento diferente do meu poderia ser justificado em alguma base razoável. Por exemplo, eu pensava anteriormente que ele era do mesmo tipo de homem que eu, mas considerado por tais e tais perspectivas, ele provou ser um tipo de homem diferente de mim em tais e tais aspectos, e eu tenho que aceitar os tratamentos diferentes como razoáveis. H. Blumer está certo em afirmar que "na medida em que um arranjo social é aceito como autoridade e legitimado, ainda que não se goste muito dele e ainda que seus efeitos sejam severos... eles [as pessoas] continuam a suportar inconveniente, desconforto,... aceitar o arranjo social como uma parte natural da ordem da vida" (Blumer, 1978, p.9). Ao contrário, somente quando eu penso que não existem razões justificáveis ou fundamento para ser tratado de uma maneira diferente de como os outros são tratados, eu experiencio o problema da igualdade-desigualdade.

4 A partir das considerações acima, eu gostaria de acentuar, em primeiro lugar, duas circunstâncias que se referem à igualdade. Uma delas, é que $o$ problema da igualdade é o problema da desigualdade no sentido em que o problema de igualdade surge através da experiência de desigualdade na interação social. E a outra, é que igualdade não pode ser experienciada em si mesma. É percebida somente através de uma melhoria da situação após experiências de desigualdade.

5 Segundo, pode-se dizer que um dos temas mais importantes na discussão do problema da igualdade é a questão da justificação de ser tratado de uma maneira diferente. De fato, muitos pesquisadores se dedicaram a este tema. A discussão aqui não trata propriamente deste tema. Ao contrário, eu gostaria de acentuar aqui que no que se refere ao problema da justificação, deve-se distinguir dois tópicos. Um deles é quais fundamentos são aceitos como razoáveis para justificar tratamentos diferentes e o outro é quais fundamentos são aceitos como razoáveis para evitar os supostos fundamentos razoáveis para justificar tratamentos diferentes. 
5.1 Os dois tópicos mencionados logo acima estão ou não em relação simétrica, ou seja, um é ou não o outro lado da mesma moeda. Se eles estão em relação simétrica, a pesquisa sobre igualdade pode ser reduzida a "encontrar fatos", isto é, julgar e decidir se desigualdade ocorre de fato ou não em uma dada relação social. E então espera-se que uma situação de igualdade possa ser alcançada simplesmente removendo "barreiras" artificiais. Essa pesquisa apenas pode ser realizada quando certos critérios ou princípios (por exemplo, um sistema legal) podem ser pressupostos para julgamento, e os mesmos critérios podem ser adotados para julgamento tanto da igualdade quanto da desigualdade.

5.2 Mas aqui uma asserção de Schutz deve ser considerada seriamente e honestamente. É a de que "rigorosamente falando, não existe uma tal coisa como fato, puro e simples. Todos os fatos são desde sempre fatos selecionados de um contexto universal pelas atividades de nossa mente. Eles são, portanto, sempre fatos interpretados...Eles comportam seus horizontes internos e externos" (Schutz, 1953, p.5). Parafraseando esta assertiva, nenhum critério ou nenhum princípio para julgar igualdade poderia ser pressuposto de situações nas quais interação social de fato ocorre, e um critério para julgar igualdade poderia ser diferente de um critério para julgar desigualdade. Por conseguinte, os dois tópicos mencionados acima não estão sempre em relações simétricas. Seguindo a assertiva schutziana, a pesquisa não estaria centrada em "encontrar fatos", mas em encontrar processos "interpretativos" ou "constitutivos" de fatos. Se for este o caso, o objetivo de provocar igualdade não consiste apenas na remoção de obstáculos existentes, mas também "na determinação criativa de novas direções" (Schutz, 1999, p. 287).

5.3 Quanto às bases para justificar os tratamentos diferentes e as bases para evitar as bases alegadamente razoáveis para o tratamento diferente, ambos devem variar dependendo das perspectivas a partir das quais são abordadas. As bases socialmente aceitas podem ou não ser aceitas pela pessoa em questão, e vice versa. Isto significa que a pesquisa sobre igualdade e desigualdade deve considerar com atenção tanto o ponto de vista subjetivo quanto o ponto de vista objetivo em relação aos tratamentos diferentes. As assertivas de Schutz sobre discriminação como um tipo de desigualdade são consideradas seriamente, a saber: "discriminação pressupõe tanto imposição de uma tipificação do ponto de vista objetivo e uma avaliação adequada desta imposição do ponto de vista subjetivo do indivíduo aflingido" (Schutz, 1957, p. 261).

6 Há, contudo, um outro tópico a ser investigado para a discussão sobre igualdade antes de questionar sobre as maneiras de justificação para os tratamentos iguais. Este tópico refere-se aos momentos nos quais as bases 
razoáveis para a própria justificação se tornam e se fazem problemáticas. Essas bases são em si mesmas geralmente assumidas como dadas na vida cotidiana, e isso significa que as próprias bases não são problemáticas na maioria dos casos. As pessoas vivem suas vidas cotidianas sem voltar-se para as maneiras de justificação por serem tratadas diferentemente. Pode-se dizer que minha expressão "eu sei que", utilizada frequentemente na Parte A da sessão II deste artigo, pode ser trocada pela expressão "eu assumo como dado que".

6.1 Na vida cotidiana, o processo de investigação de qual tipo de fundamento é adotado para justificar o tratamento diferente e o processo de voltar-se para os próprios fundamentos ocorrem simultaneamente. Mais precisamente, eles estão em uma relação reflexiva. Entretanto, eles têm que ser distinguidos um do outro. Esta distinção é o corolário da distinção schutziana entre "seleção", por um lado, e "deliberação e escolha", por outro lado. Schutz afirma que "esta situação de dúvida, criada pela seleção do ator em sua situação biográfica específica do mundo assumido como dado é a única coisa que torna possível a deliberação e escolha" (Schutz, 1951, p. 78). Na próxima sessão vou considerar brevemente os momentos nos quais as bases para justificar os tratamentos diferentes se tornam e são feitos problemáticos em si mesmos, ou seja, o problema de justificação em si mesmo surge da situação do mundo de assumir como dado.

\section{Em que momento surgem os fundamentos para a justificação da situação de assumir como dado?}

1 Antes de entrar na discussão sobre o tópico dos momentos nos quais os fundamentos para a justificação em si mesmos emergem, eu gostaria de enfatizar que este tópico está aberto para pesquisas empíricas. Os momentos de emergência dos fundamentos para a justificação são consideravelmente variados dependendo da pessoa, situação, sociedade, história e cultura. Por exemplo, a "mesma" interação pode ser o momento de emergência para a pessoa ou pode não ser o momento para a outra pessoa. Ademais, mesmo para a mesma pessoa, a "mesma" interação pode ser o momento nesta situação e pode não ser naquela outra situação. (Nestes exemplos, o termo "mesmo" significa que a interação pode ser vista como a "mesma" a partir do ponto de vista objetivo de uma terceira pessoa). Devido a estas circunstâncias dos momentos de surgimento das bases para a justificação, os dados sobre igualdade coletados por pesquisas empíricas quantitativas tendem a ser incomensuravelmente separados um do outro. Os dados deste tipo poderiam ser acumulados no sentido quantitativo, mas não poderiam ser no sentido qualitativo, isto é, deve haver pouca expectativa de aprofundar ou ampliar nosso entendimento do fenômeno de igualdade-desigualdade na pesquisa empírica quantitativa. 
1.1 Afim de escapar desta situação insuficiente da pesquisa empírica, deve ser necessário considerar que cada dado é extraído ou construído em termos de um esquema de referência, não importa se a pessoa percebe ou não que isso ocorra. Não existe uma tal coisa como um dado puro. Todo dado traz um "subscrito" remetendo ao problema sob análise (ver Schutz, 1953, p. 5; 1957, p. 234). Como bem sabido, Schutz chama tal circunstância de constructos, ou seja, dados e tipos mencionados logo acima, de "princípio da relevância" (Schutz, 1943, p. 84).

1.2 O "princípio da relevância" é válido para todos os constructos, ou seja, constructos de "senso comum" subjetivos e objetivos e constructos científicos. Porém, os constructos científicos sociais possuem uma característica adicional, porque o objetivo da ciência social é entender e/ou explicar não o mundo da ciência, mas o mundo social, o qual as pessoas entendem e/ou explicam em termos de constructos de senso comum antes que a ciência social o faça em termos de constructos científicos. Constructos das ciências sociais devem se remeter aos constructos do senso comum. Eles são "constructos de segunda ordem" (Schutz, 1953, p. 6). Esta é uma das mais famosas contribuições de Schutz.

1.3 Ciências sociais realmente têm de se remeter aos constructos do senso comum. E especialmente em uma discussão sobre os momentos nos quais emergem as bases para justificar os próprios tratamentos diferentes, toda a atenção deve ser dada não apenas aos constructos socialmente compartilhados mas também aos constructos subjetivos usados pelas pessoas em questão, porque desigualdade geralmente aparece na vida cotidiana por meio da experiência das pessoas sendo tratadas diferentemente. Considerando este ponto, voltemo-nos aos momentos de emergência dos fundamentos para a justificação.

2 Podem ser considerados dois tipos de momentos em que emergem os fundamentos justificados. Um deles é o momento em que a pessoa é tratada na interação social de maneiras diferentes do que a mesma pessoa foi tratada antes. Este é o caso em que a interação social não pode ocorrer de uma maneira antecipada. O problema surge inesperadamente. $O$ outro é o caso em que as pessoas se voltam para as bases justificadoras a despeito de serem tratadas da mesma maneira como foram tratadas antes ou têm sido tratadas. Neste caso, a interação social ocorre suavemente e o problema é intencionalmente colocado. 3 Quanto ao primeiro caso, dois tipos de momentos poderiam ser distinguidos. Tomando dois casos recentes no Japão como exemplos, vou descrever esses dois momentos brevemente.

3.1 Um deles é o caso relativo a um "estrangeiro" no Japão ano passado. Ele não havia tido a experiência de ser rejeitado na utilização de um espaço público. Ele se foi a uma casa de banho paga e se dirigia para pagar o ingresso 
de entrada no portão de entrada sem qualquer ideia se ele seria rejeitado ou não. Mas ele foi rejeitado inesperadamente. Então ele se voltou para os fundamentos pelos quais ele foi rejeitado.

3.1.1 Neste caso, ele compartilha uma autotipificação (eu sou um "estrangeiro" no Japão) com o responsável pela portaria. Ele considerou e esperava que este tipo de tipificação fosse irrelevante para desfrutar de uma casa de banho. Mas o tipo "estrangeiro" era relevante para o responsável. Neste caso, embora sua auto-tipificação corresponda substancialmente à tipificação dele pelo diretor, esta tipificação é julgada ou interpretada por diferentes sistemas de relevância. Sua atenção aos fundamentos de justificação foi causada pelo conflito entre o sistema de relevância interpretativo do diretor e o seu.

3.2 Um exemplo para o outro tipo pode ser citado do caso envolvendo a luta de sumô neste ano. Um campeão no torneio de Osaka recebe de costume um certificado de comenda no ringue de luta pelo governador de Osaka. Uma mulher foi eleita como a nova governadora na última eleição. Foi a primeira vez que uma mulher foi eleita governadora. Ao assumir o cargo, ela organizou sua agenda como um "governador" para ir e dar um certificado no ringue de acordo com o costume, isto é, da mesma maneira como todos os ex-governadores fizeram. Entretanto, seu plano de ela mesma dar um certificado foi inesperadamente rejeitado pela Associação Japonesa de Sumô pelo motivo de que "mulher" é proibida pela tradição de entrar no ringue no campo do sumô. Então ela se voltou para os fundamentos de justificação de um tratamento diferente no campo do sumô.

3.2.1 Embora uma governadora tenha sido tratada de fato da mesma maneira como todas as mulheres foram tratadas, ela foi tratada de uma maneira diferente de como foram tratados todos os ex-governadores. O tipo social "governador" era topicamente relevante para um governador e o tipo social "mulher" era topicamente relevante para a Associação de Sumô. A atenção da governadora às bases de justificação foi causada pelo conflito entre auto-tipificação de si mesma e a tipificação dela pela Associação Japonesa de Sumô.

4 Quanto ao segundo caso, um exemplo poderia ser citado do caso com o sistema japonês de sobrenomes para casais. Há uma cláusula no Código Civil Japonês de que casais devem adotar o mesmo sobrenome (\#750). Embora neste Código Civil seja permitido ao casal adotar o sobrenome da esposa ou do marido, quase todos os casais assumem como dado que a esposa abandona seu sobrenome e assume um sobrenome do marido. Seguindo tal costume de nomear, eles conduziram sua vida cotidiana sem problemas. Mas dez anos atrás algumas esposas começaram a colocar em dúvida não apenas este costume, mas também a cláusula sobre a maneira de nomear. Elas levaram adiante a demanda 
de usar seus próprios sobrenomes formalmente após seu casamento. Elas se voltaram para os fundamentos de justificação de um tratamento diferente entre a "esposa" e o "marido".

4.1 Suas dúvidas e demandas podem não ter origem nos problemas com sua interação familiar ou de parentesco. Elas, ao contrário, devem trazer problemas à harmonia da relação familiar e de parentesco. Uma das origens de suas dúvidas e demandas pode ser considerada como sendo as mudanças na situação social, por exemplo, o aumento no número de esposas trabalhadoras e a penetração e difusão de ideias feministas. Sua atenção aos fundamentos justificadores não foi causada pelo conflito entre uma auto-tipificação e uma tipificação pelo outro, como os dois casos mencionados logo acima. Foi causada, ao contrário, por uma mudança na própria auto-tipificação ou uma mudança na conotação da auto-tipificação, que foram causadas de acordo com mudanças na situação social.

\section{Conclusões}

1 Minha descrição neste ensaio é realmente muito preliminar. Há muitos tópicos deixados a serem investigados empiricamente e teoricamente. Mas posso dizer uma coisa com segurança, que o problema da igualdadedesigualdade ocorre no mundo da vida cotidiana. Este aparece do e contra o que é assumido como dado por meio da interação social. No domínio do mundo assumido como dado ou o campo do não-problemático "mostrou-se dividido por uma nova experiência não subsumível sob o quadro de referência inquestionado até agora" (ver Schutz, 1970, p. 25; 1951, p. 74).

2 Uma "nova experiência" não é apenas imposta. Ela é também intrínseca, pois cada elemento do que é assumido como dado "tem necessariamente uma característica equívoca de indeterminação” (Schutz, 1951, p. 75) e, portanto, nosso mundo da vida é "essencialmente opacidade" (Schutz, 1970, p. 152). É a razão pela qual a pessoa pode introduzir o problema da igualdade-desigualdade no mundo do que é assumido como dado. E é corolário da assertiva de que todos os fatos "possuem seu horizonte interpretativo interno e externo" (Schutz, 1953, p. 5).

3 Se este é o caso com experiências com igualdade-desigualdade, e minha descrição neste artigo mantém-se verdadeira para essas experiências, as contribuições de Schutz baseadas em sua "fenomenologia constitutiva da atitude natural" podem ser extremamente úteis para a pesquisa sobre o problema da igualdade-desigualdade no mundo da vida cotidiana. Não estou dizendo apenas seu artigo centrado e excelente, intitulado "Igualdade e as estruturas de significado do mundo social”. Quero dizer também que, se a pesquisa 
sobre igualdade-desigualdade for adequada (em termos de Schutz), a pesquisa deve considerar especialmente suas ideias sobre concepções de "significados subjetivos e objetivos", "tipificação", "relevância" e "conhecimento". Espero que este artigo possa mostrar a razão porque essas concepções elaboradas por Schutz são significativas para a pesquisa sobre igualdade e desigualdade.

\section{Referências}

BLUMER, H. Social Unrest and Collective Protest, Studies in Symbolic Interaction, 1, p. 1-54, 1978.

HARRISON, S. The Social Construction of Equality in Everyday Life, Human Studies, 23, p. 371-393, 2000.

HUSSERL, E. Die Krisis der europäischen Wissenschaften und die transzendentale Phänomenologie, Husserliana Bd. VI, Martinus Nijhoff, 1962.

OHTAKE, H. 90 Nen-dai no Shotoku Kakusa, (in Japanese), Nihon Rodo Kenkyu Zasshi, July, p. 2-11, 2000.

SATO, T. Soredemo Susumu 'Hubyodo-Shakaika', (in Japanese) Chuo-Koron, Nov. p. 92-100, 2000.

SEIYAMA, K. Churyu Hokai ha 'Monogari' ni Sunginai, (in Japanese), Chuo-Koron, Nov. p. 84-91, 2000.

SEN, A. Inequality Reexamined, Oxford University Press, 1992.

SCHUTZ, A. The Problem of Rationality in the Social World, reprinted in Collected Papers, vol. 2 (hereafter cited as “CP2”), Martinus Nijhoff, 1964, p. 64-88, 1943.

SCHUTZ, A. Choosing among Projects of Action, reprinted in Collected Papers, vol. 1, (hereafter cited as “CP1”), Martinus Nijhoff, p. 67-96, 1951.

SCHUTZ, A. Common-Sense and Scientific Interpretation of Human Action, reprinted in $C P 1$, p. 3-47, 1953.

SCHUTZ, A. Some Considerations Concerning Thinking in Terms of Barriers, edited by Lester Embree in Schutzian Social Science, Kluwer Academic Publishers, p. 287289, 1999.

SCHUTZ, A. Equality and Meaning Structure of the Social World, reprinted in CP2, p. 226-273, 1957.

SCHUTZ, A. Reflections on the Problem of Relevance, Yale University Press, 1970.

TATSUKI, T. Nihon no Keizai Kakusa, (in Japanese), Iwanami-Shoten, 1998.

Recebido em: 14/09/2010

Aprovado em: 29/06/2011 